\title{
PEMBUATAN PETA CITRA MELALUI PENGINDERAAN JAUH MENGGUNAKAN PESAWAT TERBANG TANPA AWAK (PTTA) DI DESA PETAI BARU, KECAMATAN SINGINGI, KABUPATEN KUANTAN SINGINGI, PROVINSI RIAU
}

\author{
Musthafa Akbar $^{1 *}$, Kaspul Anuar ${ }^{2}$, Romi $^{3}$, Herisiswanto ${ }^{4}$, Yohanes $^{5}$ \\ 1,2,3,4,5 Jurusan Teknik Mesin, Fakultas Teknik, Universitas Riau, Pekanbaru, Indonesia. \\ "Email: akbarmst@gmail.com
}

\begin{abstract}
High resolution image maps of an area can be used as a basis for spatial planning. In addition, high resolution image maps can also be used to inventory land use in an area. One method to build high resolution image maps is through remote sensing using Unmanned Aerial Vehicle (UAV). The advantage of build an image map through remote sensing using Unmanned Aerial Vehicle (UAV) is that the image produced is very detailed (resolution of $5 \mathrm{~cm}$ ). When compared to satellite images, the maximum resolution is only $50 \mathrm{~cm}$. In addition, taking aerial imagery using Unmanned Aerial Vehicle (UAV) is not constrained by cloud conditions, because the operation of UAV is carried out at an altitude below the clouds.

Petai Baru Village is one of the villages in Singingi District, Kuantan Singingi District, Riau Province. This village has an area of $10.5 \mathrm{~km} 2$. Petai Baru Village is in an area surrounded by forests and oil palm plantations with sandy yellow soil types. The distance from Pekanbaru City to Petai Baru Village, Singingi District is approximately $180 \mathrm{~km}$.

In 2018, a team of lecturers from the Mechanical Engineering Department of the University of Riau conducted community service activities in Petai Baru Village in the form of build high resolution image maps through remote sensing using Unmanned Aerial Vehicle (UAV). In its implementation, this community service activity began with a survey to the location which aims to explore problems related to spatial layout and availability of image maps in Petai Baru Village. In addition, the survey activity aims to plan the flyway that will be passed by Unmanned Aerial Vehicle $(U A V)$. The main activities in the form of remote sensing are carried out in accordance with the time agreed with the village, namely on 11 August 2018. The remote sensing process using Unmanned Aerial Vehicle (UAV)is assisted by students from the University of Riau and local village officials. Aerial photo data obtained through aerial photography is 125 pieces. Aerial photo data is then processed in the mosaic software to obtain output in the form of aerial maps with high resolution images. This air map is then printed on the banner and handed over to the local village head in hard copy (banner printing) and soft copy (in kml format).
\end{abstract}

Keywords-Image, Village, Maps

Abstrak
Peta citra resolusi tinggi dari suatu area dapat digunakan sebagai dasar dalam merencanakan tata ruang. Selain itu, peta citra resolusi tinggi juga dapat digunakan untuk menginventarisasi penggunaan lahan disuatu area. Salah satu metode pembuatan peta citra resolusi tinggi adalah melalui penginderaan jauh menggunakan Pesawat Terbang Tanpa Awak (PTTA). Keunggulan pembuatan peta citra melalui penginderaan jauh menggunakan Pesawat Terbang Tanpa Awak (PTTA) adalah gambar/citra yang dihasilkan sangat detail (resolusi sebesar $5 \mathrm{~cm}$ ). Jika dibandingkan dengan gambar/citra yang dihasilkan satelit, resolusi maksimumnya hanya sebesar $50 \mathrm{~cm}$. Selain itu, pengambilan citra udara menggunakan PTTA tidak terkendala kondisi awan, karena pengoperasiaan PTTA dilakukan pada ketinggian di bawah awan.

Desa Petai Baru merupakan salah satu desa yang berada di Kecamatan Singingi, Kabupaten Kuantan Singingi, Provinsi Riau. Desa ini memiliki luas wilayah sebesar 10,5 km². Desa Petai Baru berada di area yang dikelilingi oleh hutan dan perkebunan kelapa sawit dengan jenis tanah kuning berpasir. Jarak dari Kota Pekanbaru ke Desa Petai Baru, Kecamatan Singingi lebih kurang 180 km. 
Pada tahun 2018, Tim dosen dari Jurusan Teknik Mesin Universitas Riau melaksanakan kegiatan pengabdian masyarakat di Desa Petai Baru dalam bentuk pembuatan peta citra resolusi tinggi melalui penginderaan jauh menggunakan Pesawat Terbang Tanpa Awak (PTTA). Dalam pelaksanaanya, kegiatan pengabdian masyarakat ini diawali dengan kegiatan survey ke lokasi yang bertujuan untuk menggali permasalahan terkait tata ruang dan ketersediaan peta citra di Desa Petai Baru. Selain itu, kegiatan suvey ini bertujuan untuk merencanakan jalur terbang yang akan dilewati oleh wahana pesawat terbang tanpa awak. Kegiatan utama berupa penginderaan jauh dilaksanakan sesuai dengan waktu yang disepakati dengan pihak desa yaitu pada tanggal 11 Agustus 2018. Proses penginderaan jauh menggunakan pesawat terbang tanpa awak ini dibantu oleh mahasiswa kukerta Universitas Riau dan perangkat desa setempat. Data foto udara yang didapat melalui pemotretan udara yaitu sebanyak 125 buah. Data foto udara ini kemudian diolah pada software mosaic agar didapat output berupa peta udara dengan citra resolusi tinggi. Peta udara ini kemudian dicetak pada banner dan diserahkan kepada kepala desa setempat dalam bentuk hard copy (cetak banner) dan softcopy (dalam format $\mathrm{kml}$ ).

Kata Kunci-Citra, Desa, Peta

\section{PENDAhULUAN}

Desa Petai Baru merupakan salah satu desa yang berada di Kecamatan Singingi, Kabupaten Kuantan Singingi, Provinsi Riau. Desa ini memiliki luas wilayah sebesar $10,5 \mathrm{~km}^{2}$. Desa Petai Baru berada di area yang dikelilingi oleh hutan dan perkebunan kelapa sawit dengan jenis tanah kuning berpasir. Jarak dari Kota Pekanbaru ke Desa Petai Baru, Kecamatan Singingi lebih kurang 200 km [1].

Desa Petai Baru menjadi desa yang paling maju dibandingkan desa - desa tetangganya. Hal ini dapat dilihat dari keberadaan fasilitas publik yang tersedia di desa ini. Dengan memanfaatkan dana desa bantuan pemerintah pusat, pertumbuhan penggunaan lahan untuk fasilitas publik seperti sarana kesehatan, sarana pendidikan dan olahraga di Desa Petai Baru berkembang cukup pesat. Selain itu, penggunaan lahan untuk perkebunan kelapa sawit di Desa Petai Baru juga berkembang cukup pesat. Pertumbuhan penggunaan lahan ini perlu didukung dengan perencanaan tata ruang yang baik. Jika tidak didukung dengan rencana tata ruang yang baik, akan mengakibatkan ketidakteraturan bangunan, keadaan drainase yang kurang baik dan akses jalan yang sulit dilewati oleh kendaraan (mobil) pada pemukiman padat penduduk [2].

Dalam mendukung upaya perencanaan tata ruang yang baik, data dukung terkait peta citra beresolusi tinggi yang bersifat real time perlu dibuat. Selain untuk mendukung perencanaan tata ruang, peta citra resolusi tinggi juga dapat dimanfaatkan untuk memperjelas batas-batas Desa Petai Baru dengan Desa tetangganya [3]. Untuk itu, tim dosen dari Jurusan Teknik Mesin Universitas Riau berencana melakukan kegiatan pengabdian masyarakat dalam bentuk pembuatan peta citra resolusi tinggi melalui penginderaan jauh menggunakan Pesawat Terbang Tanpa Awak (PTTA) di Desa Petai Baru, Kecamatan Singingi, Kabupaten Kuantan Singingi, Provinsi Riau. Dalam pelaksanaanya, kegiatan pengabdian masyarakat ini direncanakan melibatkan mahasiswa kukerta Universitas Riau, perangkat desa dan masyarakat setempat.

\section{METODE}

Berikut dijelaskan metode yang akan dilakukan dalam pembuatan peta citra melalui penginderaan jauh menggunakan Pesawat Terbang Tanpa Awak (PTTA) di Desa Petai Baru, Kecamatan Singingi, Kabupaten Kuantan Singingi, Provinsi Riau:

\subsection{Survey awal}

Mengadakan survey awal ke lokasi pengabdian yang bertujuan untuk menggali permasalahan terkait perencanaan tata ruang dan ketersediaan peta citra di Desa Petai Baru. Diskusi awal ini juga ditujukan untuk mengkoordinasikan encana pelaksanaan kegiatan, menggali potensi keterlibatan 
mitra serta pihak lainya. Kegiatan survey awal ini dilaksanakan dalam rangka menysusun proposal pengabdian untuk mendapatkan analisis situasi terhadap khalayak masyarakat (mitra).

\subsection{Persiapan Kegiatan Pengabdian Masyarakat}

\section{a. Pembuatan Wahana Pesawat Terbang Tanpa Awak}

Kegiatan pembuatan wahana pesawat terbang tanpa awak Atha Mapper 2150 dilakukan berdasarkan desain dari tim robot terbang serindit aero. Proses pembuatan wahana pesawat terbang tanpa awak ini, diawali dengan menyiapkan bahan dan peralatan yang diperlukan. Bahan yang dibutuhkan diantaranya, fiberglass cloth, resin epoxy, kuas, wax, plastik vakum, dempul kasar, dempul halus, cat epoxy, cat inti dan cat clear. Peralatan yang diperlukan diantaranya pompa vakum, tool set, gerinda tangan dan bor listrik.

Bagian airframe yang pertama kali dibuat yaitu bagian fuselage. Bagian fuselage dicetak dengan menggunakan cetakan yang telah ada. Proses pencetakan dilakukan menggunakan bahan fiberglass cloth dicampur dengan resin epoxy. Agar gelembung udara tidak terperangkap, maka dilakukan proses pemakuman dengan bantuan pompa vakum. Setalah fuselage selsai dicetak, selanjutnya dilakukan proses finishing bagian fuselage dengan menggunakan dempul halus dan kasar. Proses ini dilanjutkan hingga pengecatan, mulai dari pengecatan epoxy samapai dengan pengecatan clear. Berikut ditampilkan gambar 1 proses pengecatan bagian fuselage dari pesawat terbang tanpa awak.

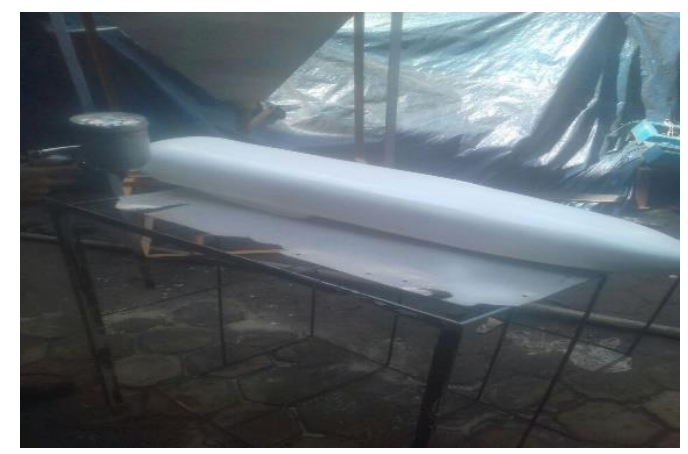

Gambar 1. Proses pengecatan bagian fuselage dari pesawat terbang tanpa awak.

Tahap selanjutnya dari pembuatan pesawat terbang tanpa awak yaitu pembuatan bagian sayap dan ekor. Dalam pembuatan sayap dan ekor, bahan-bahan yang dibutuhkan yaitu material hard foam, lem bakar, stiker cutting, aluminium spar dan kayu balsa. Proses pembuatan sayap dan ekor diaali dengan memotong material hard foam sesuai dengan dimensi dari desain sayap dan ekor wahana pesawat terbang tanpa awak Atha Mapper 2150. Pembentukan sayap dan ekor secara tiga dimensi dilakukan dengan memanfaatkan hot wire (kawat panas) dan mal triplek dari airfoil sayap dan ekor. Setelah bagian sayap dan ekor terbentuk, dilakukan proses pengamplasan sampai sayap dan ekor terlihat rapi. Selanjutnya dilakukan proses laminasi dengan menggunakan balsa sheet dan cutting sticker. Berikut ditampilkan gambar 2 bagian sayap yang telah dilaminasi dengan balsa sheet

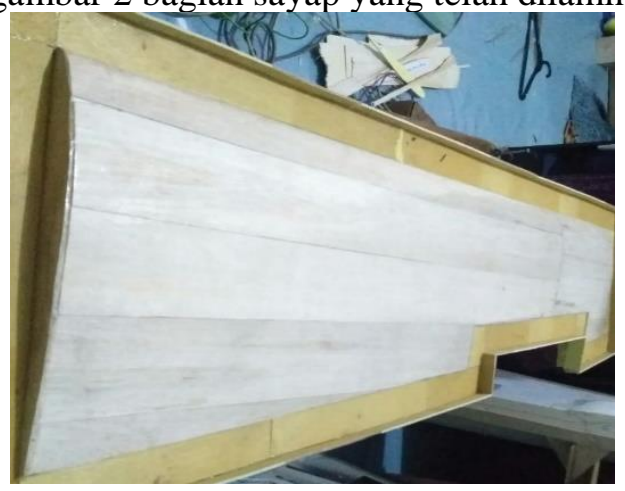

Gambar 2. Bagian sayap yang telah dilaminasi dengan balsa sheet

Setelah bagian fuselage, sayap dan ekor wahana pesawat terbang tanpa awak dibentuk, tahap selanjutnya yaitu dilakukan proses assembli dari ketiga bagian airframe utama dari pesawat terbang tanpa awak Atha mapper 2150. Proses asembli diawali dengan menyatukan bagian fuselage dengan 
bagian ekor dari wahana pesawat terbang tanpa awak. Proses penyatuan dilakukan menggunakan tambahan material aluminium berongga, baut dan mur. Setelah terbentuk asembli dari bagian fuselage dan ekor, selanjutnya dilakukan assembli bagian fuselag dengan bagian sayap. Proses penyatuan kedua bagian ini, dilakukan dengan menggunakan tambahan material aluminium spar, mur dan baut. Penyatua kedua bagian ini dilakukan tepat pada dudukan sayap yang tedapat pada bagian atas dari fuselage. Berikut ditampilkan gambar 3 hasil dari asembli bagian airframe utama pesawat terbang tanpa awak atha mapper 2150 .

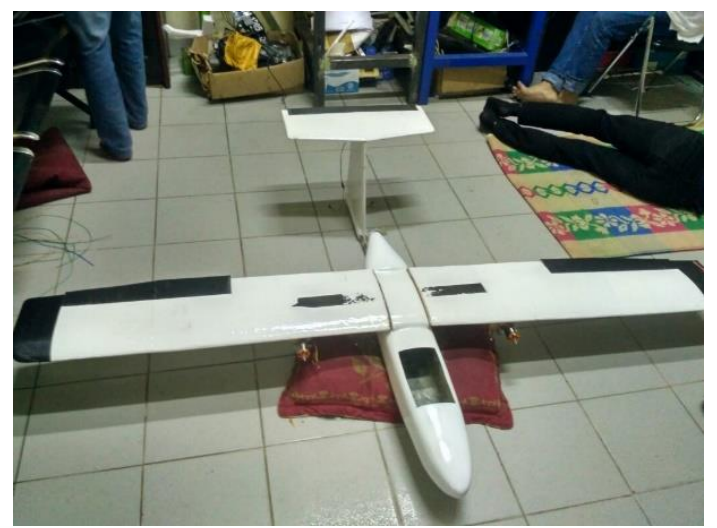

Gambar 3. Hasil dari asembli bagian airframe utama pesawat terbang tanpa awak

Setelah semua bagian airframe utama pesawat terbang tanpa awak diasembli, berikutnya dilakukan proses installasi perangkat elektronik. Proses installasi ini diawali dengan memasang bagian motor tepat di dudukanya yang terdapat pada kedua bagian sayap. Setelah selesai pemasangan motor, selanjutnya dilakukan proses intallasi motor servo pada bagian aileron, elevator dan rudder. Perangakat elektronik lainya seperti batere, esc, power modul, telemetri dan pengontrol pesawat, proses installasinya dilakukan pada bagian akhir. Berikut ditampilkan gambar 4. wahana pesawat terbang tanpa atha mapper 2150, yang telah dilakukan proses installasi perangkat elektronik.

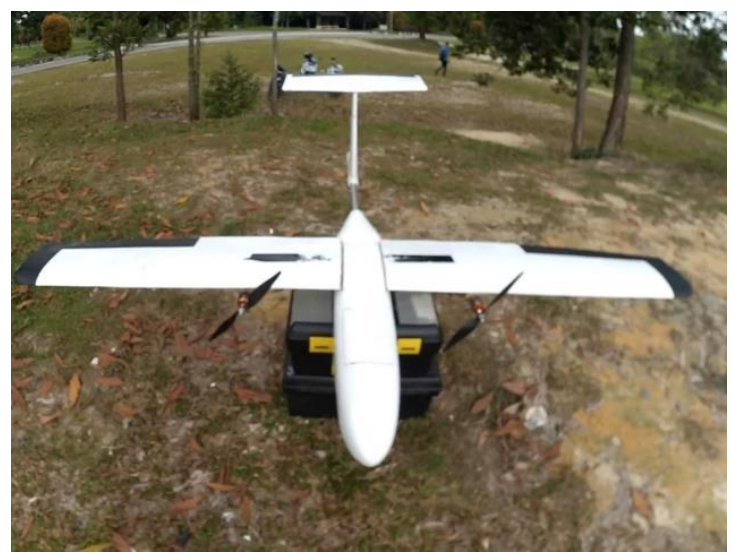

Gambar 4. wahana pesawat terbang tanpa atha mapper 2150, yang telah dilakukan proses intallasi perangkat elektronik

Wahana pesawat terbang tanpa awak yang telah selesai diproduksi, selanjutnya dilakukan proses uji terbang dalam menjalankan misi pemetaan melalui foto udara. Proses uji terbang ini dilakukan di lapangan dekat gedung gasing Universitas Riau. uji terbang dilakukan pada ketinggian 150 meter dari atas permukaan tanah. Uji terbang dalam menjalankan misi pemetaan melalui foto udara suskes menghasilkan data foto udara sesuai dengan yang diharapkan. Berikut ditampilkan gambar 5 wahana pesawat terbang tanpa awak dalam uji coba menjalankan misi pemetaan melalui foto udara. 


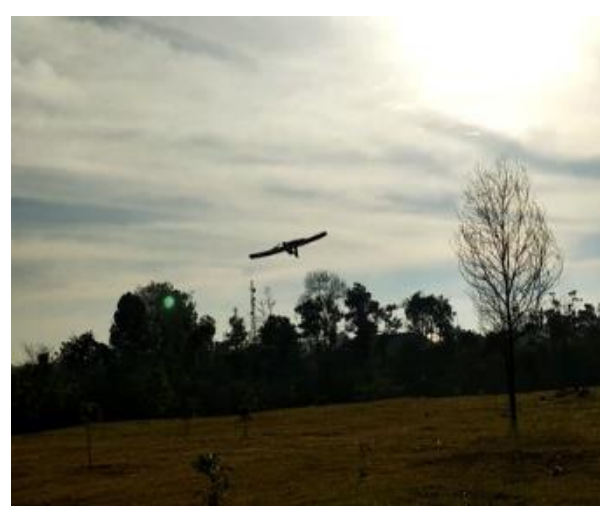

(a)

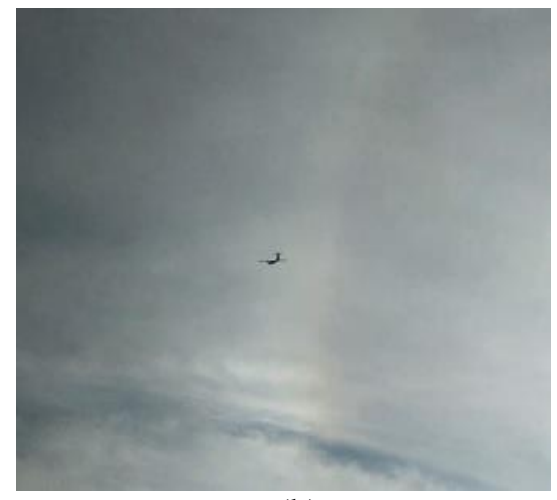

(b)

Gambar 5. wahana pesawat terbang tanpa awak dalam uji coba menjalankan misi pemetaan melalui foto udara. (a) fase take off (b). fase cruise

\subsection{Persiapan Peralatan Pendukung Kegiatan Pengabdian}

Pada tahap ini, tim pengabdian melakukan tahap persiapan peralatan pendukung dan persiapan keberangkatan ke lokasi pengabdian. Peralatan yang disiapkan oleh tim diantaranya penunjuk ground control point, batere lithium dalam kondisi full charge, karet bungee chord, box soft case untuk pesawat terbang tanpa awak, dan spanduk kegiatan pengabdian. Selain itu perencanaan area untuk take off, landing dan jalur terbang juga akan ditentukan sebelum keberangkatan. Pesawat terbang tanpa awak yang digunakan dilokasi pengabdian sebanyak dua unit Pesawat Terbang Tanpa Awak (PTTA) Atha Mapper.

\subsection{Pelaksanaan}

Pelaksanaan pengabdian dilokasi Desa Petai Baru, dalam bentuk pembuat peta citra melalui pemetaan udara, dilakukan dengan bantuan dari mahasiswa kukerta tematik Universitas Riau. Mahasiswa kukerta bertugas untuk menrekomendasikan lokasi yang cocok untuk wahana pesawat terbang tanpa awak dalam melakukan proses take off dan landing. Selain itu mahasiswa juga bertugas dalam menertibkan anak-anak yang kebetulan datang ke lokasi untuk melihat pesawat terbang tanpa awak dalam menjalankan misi pemetaan melalui foto udara. Berikut ditampilkan gambar 6 Proses persiapan pengambilan data foto udara dilokasi pengabdian.

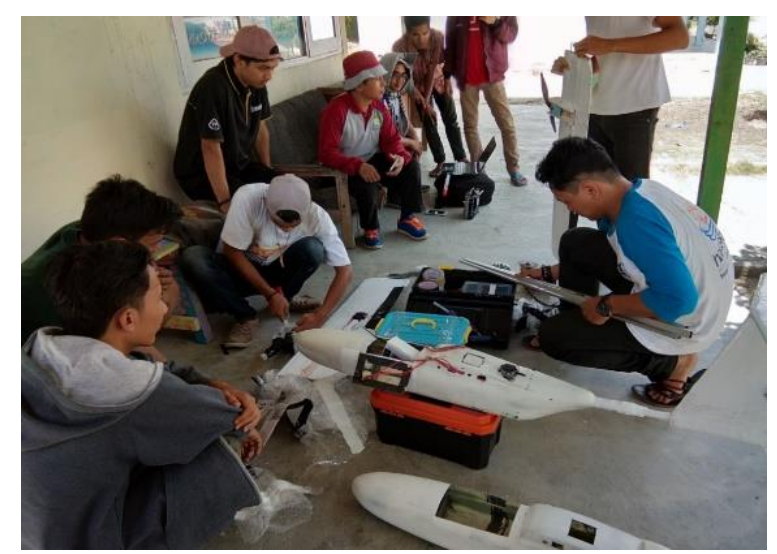

Gambar 6. Proses persiapan pengambilan foto udara di Desa Petai Baru

Proses pengambilan data citra foto udara dilakukan dengan menggunakan Pesawat Terbang Tanpa Awak (PTTA) yang dilengkapi dengan kamera 25 Mega pixel. Selama melaksanakan misi pencitraan jarak jauh, Pesawat terbang Tanpa Awak (PTTA) terbang secara autonomous pada ketinggian tetap sebesar 150 meter diatas permukaan laut.

Dari hasil pengambilan foto udara di Desa Petai Baru, didapat 150 buah foto udara dengan citra resolusi tinggi. Foto ini kemudian diolah menggunakan software agisoft photo scan agar dihasilkan sebuah peta berbentuk ortophoto dengan citra resolusi tinggi. Peta ini kemudian diprint 
pada banner dan diserahkan kepada Kepala Desa Petai Baru. Selain dalam bentuk banner, Peta citra ini juga diserahkan dalam bentuk soft file. Berikut ditampilkan gambar 7 salah satu hasil photo udara di Desa Petai Baru, Kecamatan Singingi, Kabupaten Kuantan Singingi.



Gambar 7. Salah satu hasil photo udara di Desa Petai

\subsection{Penyusunan dan pembuatan laporan kegiatan}

Laporan disusun sesuai format laporan pengabdian kepada masyarakat dan diperbanyak untuk masing - masing anggota pelaksanaan.

\section{HASIL DAN PEMBAHASAN}

Kegiatan pengabdian kepada masyarakat di Desa Petai Baru, Kecamatan Singingi, Kabupaten Kuantan Singingi, bertujuan untuk menghasilkan peta citra resolusi tinggi melalui foto udara. Proses kegiatan pengambilan data foto udara dilakukan menggunakan pesawat terbang tanpa awak yang terbang pada ketinggian 150 meter dari atas permukaan tanah. Kegiatan pengambilan data foto udara di Desa Petai Baru, Kecamatan Singingi, dilaksanakan pada tanggal 11 Agustus 2018 dengan bantuan mahasiswa kukerta tematik Universitas Riau dan perangkat Desa Petai Baru. Proses pengambilan data foto udara tidak mengalami hambatan yang berarti dikarenakan kondisi cuaca yang cerah. Hasil dari foto udara kemudian dilakukan proses orthomosaic pada software agisoft photoscan. Proses orthomosaic ini menghasilkan output berupa gabungan seluruh foto udara yang ada, menjadi kesatuan utuh peta dengan citra resolusi tinggi. Peta citra resolusi tinggi pada Desa Petai Baru ini mengandung koordinat GPS, sehingga data peta citra dalm format KML, bisa dioverlay pada software google earth. Berikut ditampilkan gambar 8 peta citra resolusi tinggi pada wilayah Desa Petai Baru, Kecamatan Singingi.

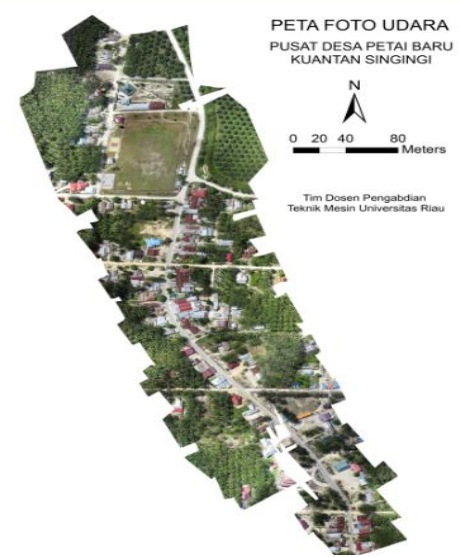

Gambar 8. Peta citra resolusi tinggi pada wilayah Desa Petai Baru

Hasil dari peta citra resolusi tinggi ini kemdian di cetak pada banner dan disimpan datanya pada flashdisk untuk diserahkan kepada Kepala Desa Petai Baru, Kecamatan Singingi. Proses 
penyerahan peta foto udara ini juga melibatkan dosen DPL kukerta tematik Unversitas Riau di Desa Petai Baru. Berikut ditampilkan gambar 9 proses penyerahan data foto udara kepada Kepala Desa Petai Baru.

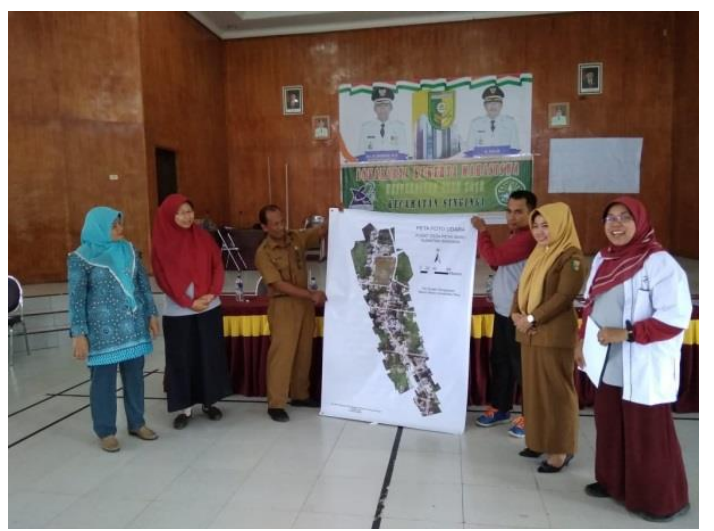

Gambar 9. Proses penyerahan data foto udara kepada Kepala Desa Petai Baru

\section{KESIMPULAN}

Kegiatan pengabdian kepada masyarakat di Desa Petai Baru yang dilaksanakan oleh tim pengabdian berhasil mencapai tujuanya. Hal ini terlihat dari data foto udara yang berhasil didapat oleh tim pengabdian melalui penginderaan jauh menggunakan pesawat terbang tanpa awak atha mapper 2150. Data foto udara ini berhasil diolah menggunakan software agisoft photoscan agar dihasilkan output berupa kesatuan foto udara dalam bentuk petac citra resolusi tinggi di wilayah Desa Petai Baru. Selain itu, kegiatan pengabdian kepada masyarakat ini juga menghasilkan satu buah artikel ilmiah yang akan disubmit pada jurnal pengabdian kepada masyarakat.

\section{SARAN}

Peta geospasial dalam bentuk foto udara yang dihasilkan oleh tim pengabdian hendaknya dapat dikembangkan oleh perangkat kelurahan terkait informasi geosapsial kependudukan lainya, sesuai dengan kebutuhan kelurahan. Sesuai dengan petunjuk yang diberikan tim pengabdian, proses editing peta geospasial dapat dilakukan dengan mudah oleh perangkat kelurahan

\section{UCAPAN TERIMA KASIH}

Tim menyadari bahwa dalam kegiatan pengabdian ini telah banyak pihak yang membantu. Oleh karena itu kami mengucapkan terima kasih kepada Bapak Prof. Dr. Almasdi Syahza, SE., MP selaku Ketua Lembaga Penelitian dan Pengabdian Kepada Masyarakat Universitas Riau

\section{DAFTAR PUSTAKA}

[1] Badan Pusat Statistik. Kecamatan Singingi Dalam Angka. 2017. Kuantan Singingi.

[2] Hidayat,(2005), Seri Panduan Pemetaan Partisipatif No. 2 - Mengenalkan Pemetaan Partisipatif,Garis Pergerakan, Bandung.

[3] Shofiyanti, Rizatus. 2011. Teknologi Pesawat Tanpa Awak Untuk Pemetaan Dan Pemantauan Tanaman Dan Lahan Pertanian. Jurnal Infromatika Pertanian. 2011 ; 20 (2) : 58 -64 